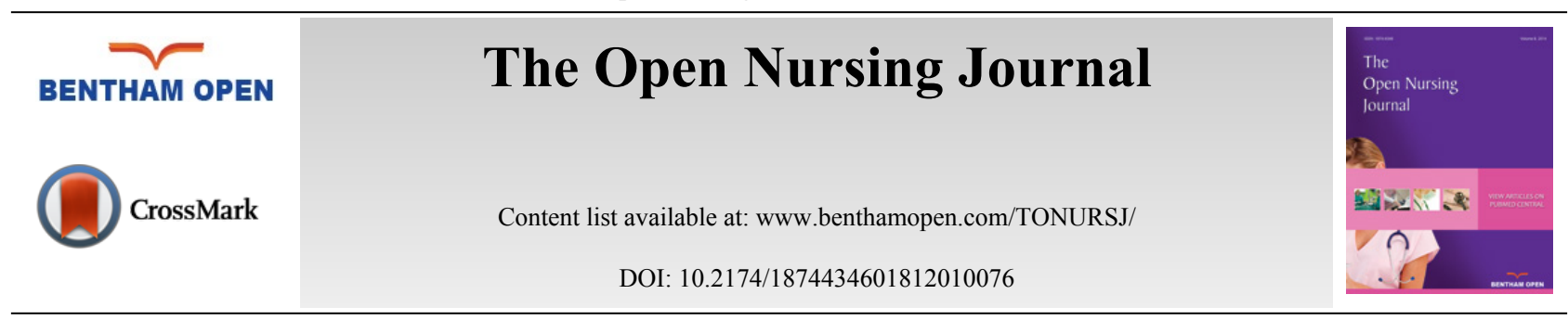

DOI: $10.2174 / 1874434601812010076$

RESEARCH ARTICLE

\title{
Validation and Assessment of Osteoporosis Self-Efficacy Among Iraqi General Population
}

\author{
Mohanad Naji Sahib* \\ Faculty of Pharmacy, Al-Rafidain University College, Palestine street, 10052, Baghdad, Iraq
}

Received: December 07, 2017

Revised: April 18, 2018

Accepted: April 27, 2018

\section{Abstract:}

\section{Background:}

Poor quality of life, fractures and disability are the consequences of preventable osteoporosis.

\section{Objectives:}

The aims of this study were to validate and assess Osteoporosis Self-efficacy Scale (OSES-A) Arabic version among Iraqi general population.

\section{Methods:}

A cross-sectional study with a random cluster sampling method from the community was used. Forward-backward-forward translation method was used to translate the questionnaire from English to Arabic. Beside OSES-A, Osteoporosis Knowledge Tool $(\mathrm{OKT})$ and Osteoporosis Health Belief Scale (OHBS) Arabic versions were used to assess osteoporosis preventive behaviours.

\section{Results:}

The results showed good face validity and reliability. The construct validity showed two factors which explain $80.86 \%$ of the variance. In addition, the result showed low self-efficacy score $(658.43 \pm 222.014)$ with $83.33 \%$ were found to have low OSES-A level. There were significant associations between age, gender, and self-reported osteoporosis with OSES-A levels. In addition, there were significant differences between age, gender, marital status, family history of osteoporosis, self-reported osteoporosis and osteoporosis diagnosis or screening in relation to total OSES-A scores. Moreover, there were positive correlations between the OSES-A total score with total knowledge and health belief. Multivariate analysis revealed that OKT levels, OHBS levels, age and gender were predictors for OSES-A levels.

\section{Conclusion:}

This study showed good cultural adaptation and psychometric properties of OSES-A tool and could be used in any osteoprotective educational program.

Keywords: Arabic, General population, Osteoporosis, Preventive behavior, Self-efficacy, Calcium, Vitamin D.

\section{INTRODUCTION}

Osteoporosis (OP) is the main cause of hip, spine, and wrist fractures which is due to the decrease in bone mineral density [1]. Poor quality of life, costly rehabilitation, disability and premature death are the consequences of this preventable disease [2]. Both genders are at risk of OP [3]. As with other chronic diseases, prevention is critically important in preventing OP. Lifestyle modification is the key component in this prevention process to increase bone mass density. Managing modifiable risk factors like regular weight-bearing exercise, increasing calcium and vitamin D

\footnotetext{
"Address correspondence to this author at the Faculty of Pharmacy, Al-Rafidain University College, Palestine street, 10052, Baghdad, Iraq; Tel: +00964-07723607555; E-mail: mohanad_pharm@yahoo.com
} 
intake, reducing smoking and alcohol intake are the cornerstone in preventing OP [4 - 6].

Although knowledge is crucial for healthy life style behaviors, it is solely not enough for the changing behaviors [3, 7 - 9]. Healthcare professionals can develop and implement a specific educational program according to good understanding of populations' belief and self-efficacy as changing lifestyle and healthy behaviors at a younger age will have a greater impact on the prevalence of OP as with other chronic diseases [10 - 13].

By definition, self-efficacy is the confidence of the person in terms of his/her capacity of coping with the difficulties in organizing and implementing healthy behavior activities [14]. Moreover, it is known that increasing the person's selfefficacy perception is an effective way to gain positive healthy behaviors [15 - 18]. Therefore, increasing knowledge, health belief and strengthening the self-efficacy perceptions of the society are substantial to prevent osteoporosis [8]. Therefore, the aims of this study were to validate and assess the self-efficacy toward OP in Iraqi general population.

\section{MATERIALS AND METHODS}

\subsection{Study Design and Participants}

A community based, cross-sectional study was conducted from November 2016 to February 2017 in Baghdad city, Iraq. Baghdad city has two large areas named Al-Kharkh and Al-Rusafa. Three districts were selected by random cluster sampling method from these areas. The community pharmacies where the undergraduate students underwent training in these districts were used to invite the participants. Systematic samples were randomly selected. A structured interview included collection of the socio-demographic and translated OSES-A data. Each participant was interviewed individually by the researcher or a trained $5^{\text {th }}$ year undergraduate student after obtaining written or verbal informed consent. Some of participants gave only verbal informed consent because they considered it impolite behavior given that they had already given verbal consent for participation. The study protocol and ethical approval (including verbal informed consent) were approved by the Scientific Committee of Al-Rafidain University Collage, Baghdad, Iraq.

\subsection{Sample Size}

A recommendation suggested that at least 5 subjects per item are needed to evaluate the reliability and validity of a questionnaire [19]. The original OSES consist of 12 questions; therefore 60 participants were needed for the purpose of validation. However, for factor analysis, it is preferable to use 300 subjects [20]. Moreover, with this number of participants, it would be possible to discriminate between high and low correlations in measuring correlations [21]. Only 400 participants were accepted to be involved in this study, however, 45 of them were ineligible due to incomplete responses. Therefore, only 355 participants were selected for this study. Thirty participants of them were randomly selected for the pilot study in face validation step of the translated questionnaire and not included in the final analysis. Moreover, 25 participants from the sample population were randomly selected for test- retest within 1-2 weeks.

\subsection{Instruments and Measurements}

All participants completed the structured questionnaires including OSES-A. The original OSES is in English language and designed to assess self-efficacy of behaviors toward OP [22, 23]. The OSES is a twelve items rated by individual on a $100 \mathrm{~mm}$ visual analogue scale to assess the confidence in performing osteoporosis preventive behaviors. The OSES has two subscales namely: OSES-Exercise and OSES-Calcium. The possible total score range from 0 to 1200 with each subscale range score from 0 to 600 . A cut-off point (858) was used to categorize the osteoporosis selfefficacy scores into two levels: low and high OSES-A levels [24].

Beside OSES-A, unpublished but valid and reliable Osteoporosis Knowledge Tool (OKT-A) and Osteoporosis health belief Scale (OHBS-A) Arabic version tools, were administered before OSES-A, respectively, according to the developer instructions. Also, the original OKT and OHBS are in English language and designed to assess OP knowledge and health beliefs about developing osteoporosis, respectively [23, 25]. The OKT is 24 multiple-choice items regarding risk factors and its prevention. From 0 to 24 is the possible score range and the highest value indicate the highest level knowledge score. While, the OHBS consist of 42- likert type scale $(1=$ strongly disagree, $5=$ strongly agree). The total possible score range from 42 to 210. Cut-off points (14 and 169) were used to categorize OKT-A and OHBS-A scores into two levels: low and high, respectively [26, 27].

\subsection{Instrument Translation and Face Validity}

Forward-backward-forward translation method was used to translate the questionnaire from English into Arabic 
according to translation international guidelines including forward translation, reconciliation, reverse translation, debriefing [28 - 30]. The translation process was conducted by two independent, expert translators. Thereafter, an expert panel of eight clinical pharmacists and the researcher reviewed the Arabic version for reconciliation. Then, backtranslation of the reconciled version was carried out by another two independent expert translators. Subsequently, discussions between the expert panel, translators, and the researcher were held to resolve any inconsistencies and check the capacity of the items to measure the construct that it proposes to measure then a final version was decided (face validity process) [31].

Finally, a pilot study was conducted by distributing the questionnaire to 30 participants and the questionnaire was modified according to their feedback after discussions between the expert panel, and the researcher. Those 30 participants were excluded from the final study outcome and analysis.

\subsection{Construct Validity}

Exploratory Factor Analysis (EFA) was examined to found the factor structures of OSES-A. A principal axis factoring method for extraction with direct Oblimin (Oblique) rotations was used for EFA. The criteria for EFA were: factor loading greater than 0.40, Kaiser-Meyer-Olkin (KMO) value ( $>0.5)$, Bartlett's test of sphericity (significant level $<0.05$ ). The number of factors retain were depend on: Kaiser's criterion (eigenvalue $\geq 1.0$ ) and theoretical meaning of the rotated factors [32].

\subsection{Reliability}

Reliability with a minimum acceptable criterion above 0.5 was applied to measure the consistency of a measurement item [33]. The internal consistency was evaluated using Cronbach's alpha and corrected item total correlations between the scales and their corresponding items (correlation of $<0.20$ is considered poor). Pearson's correlation coefficient was used to evaluate test-retest reliability [19].

\subsection{Statistical Analysis}

The statistical analysis of the validation processes included assessing construct validity and reliability (Cronbach's alpha and test-retest). Descriptive statistics, percentages, and frequencies were used as appropriate. The chi square $\left(\chi^{2}\right)$ test was employed for categorical variables to find any association, whereas for continuous data, Mann-Whitney U and Kruskal-Wallis tests were used to evaluate the differences between the groups when required. In addition, logistic regression analysis using backward method was used to identify the factors affecting OSES-A. Predictive Analytics Software (PASW) version 19.0 was used to analyze data in this study and significance level was set at $P$ value $<0.05$.

\section{RESULTS}

\subsection{Socio-Demographic}

The age of the participants was a range between 18 to 87 years with an average of $41.82 \pm 12.452$ years. Nearly $46 \%$ of respondents were male. About $79 \%$ of the respondents had educational level more than 12 years. About $23 \%$ of the respondents were single and around 38\% had monthly income less than 500,000 Iraq Dinar (IQD; 1 US dollar is equivalent to 1,250 IQD). By employing the recommended scoring method, the mean scores $(\mathrm{M} \pm \mathrm{SD})$ of the OSES-A was $658.43 \pm 222.014$ which considered low.

Table 1 shows the distribution of the two levels of osteoporosis self-efficacy and the demographic data results. Only $16.67 \%$ of the study population was found to have high OSES-A level. The results showed significant differences between the following independent variables in relation to total OSES-A scores: age, gender, marital status, family history of osteoporosis, self-reported osteoporosis and osteoporosis diagnosis or screening. In addition, there were significant associations between ages, gender, and self-reported osteoporosis with OSES-A levels (Table 1). Furthermore, the results revealed low self-efficacy in all dimensions (less than $60 \%$ ) with the lowest value appeared in the exercise subscales $(51.03 \%)$. 
Table 1. Demographic characteristics of participants; Data expressed as $\mathrm{M} \pm \mathrm{SD}$ or frequency (percentage, $\%$ ).

\begin{tabular}{|c|c|c|c|}
\hline Characteristics & Total samples $(\mathbf{N}=\mathbf{3 0 0})$ & $\begin{array}{c}\text { Low self-efficacy } \\
(\mathbf{N}=\mathbf{2 5 0})\end{array}$ & High self-efficacy $(\mathrm{N}=50)$ \\
\hline 12 item OSES-A score & $658.43 \pm 222.014$ & $591.96 \pm 174.429$ & $990.80 \pm 104.371$ \\
\hline OSES-A exercise & $306.17 \pm 153.752$ & $265.72 \pm 131.658$ & $508.40 \pm 78.020$ \\
\hline OSES-A calcium & $352.27 \pm 112.667$ & $326.24 \pm 99.098$ & $482.40 \pm 82.575$ \\
\hline $\operatorname{Age}^{\mathrm{a} *}$ & - & - & - \\
\hline$\leq 44$ & 59.7 & 56.8 & 74.0 \\
\hline$\geq 45$ & 40.3 & 43.2 & 26.0 \\
\hline Gender $^{\mathrm{b} *}$ & - & - & - \\
\hline Male & 46 & 43.2 & 60.0 \\
\hline Female & 54 & 56.8 & 40.0 \\
\hline Marital status $^{\mathrm{c}}$ & - & - & - \\
\hline Single & 23 & 21.6 & 30.0 \\
\hline Not single & 77 & 78.4 & 70.0 \\
\hline Educational levels & - & - & - \\
\hline$<12$ years & 21 & 22.0 & 16.0 \\
\hline$\geq 12$ years & 79 & 78.0 & 84.0 \\
\hline Employment status & - & - & - \\
\hline Working & 84 & 84.4 & 82.0 \\
\hline Not working & 16 & 15.6 & 18.0 \\
\hline Monthly income (ID) & - & - & - \\
\hline$\leq 500,000$ & 38 & 38.4 & 36.0 \\
\hline$>500,000$ & 62 & 61.6 & 64.0 \\
\hline Living place & - & - & - \\
\hline Rural & 22 & 21.2 & 26.0 \\
\hline Urban & 78 & 78.8 & 74.0 \\
\hline Ever heard about osteoporosis & - & - & - \\
\hline No & 7 & 7.2 & 6.0 \\
\hline Yes & 93 & 92.8 & 94.0 \\
\hline Osteoporosis diagnosis or screening ${ }^{c}$ & - & - & - \\
\hline No & 82 & 80.8 & 88.0 \\
\hline Yes & 18 & 19.2 & 12.0 \\
\hline self-reported osteoporosis $^{\mathrm{b}} * *$ & - & - & - \\
\hline No & 89.3 & 87.2 & 0.0 \\
\hline Yes & 10.7 & 12.8 & 100.0 \\
\hline Family history of osteoporosis ${ }^{c}$ & - & - & - \\
\hline No & 72.7 & 72.4 & 74.0 \\
\hline Yes & 27.3 & 27.6 & 26.0 \\
\hline Family history of fracture & - & - & - \\
\hline No & 59 & 58.0 & 64.0 \\
\hline Yes & 41 & 42.0 & 36.0 \\
\hline Smoking habit & - & - & - \\
\hline Not smoking & 79.3 & 79.2 & 80.0 \\
\hline Smoking & 20.7 & 20.8 & 20.0 \\
\hline Alcohol habit & - & - & - \\
\hline Non alcoholic & 99.3 & 99.6 & 98.0 \\
\hline alcoholic & 0.7 & 0.4 & 2.0 \\
\hline
\end{tabular}

IQD: Iraqi dinar; significant association between groups ${ }^{*} P<0.05$, ${ }^{*} * P<0.01$; significant difference ${ }^{\mathrm{a}} P<0.001,{ }^{\mathrm{b}} P<0.01,{ }^{\mathrm{c}} P<0.05$.

\subsection{Validity}

\subsubsection{Face Validity}

As a result of the extensive translation method and pilot testing, qualitative face validity was guaranteed. 


\subsubsection{Exploratory Factor Analysis (EFA)}

In this study, a principal axis factoring analysis method was conducted on the 12 items with direct Oblimin (Oblique) rotations. Upon examination of the correlation matrices, a majority of the results showed a correlation larger than 0.3. The Kaiser-Meyer-Olkin (KMO) value was 0.913 which indicated that the data set was appropriate for EFA as it was greater than 0.5 [32]. The last measure was the Bartlett's Test of Sphericity which was found to be highly significant $\left(\chi_{(66)}^{2}=3835.496 ; P<0.001\right)$.

These results allowed us to identify a factor model using the EFA approach [34, 35]. In addition, the analysis revealed two factors, with eigenvalues greater than one that explained $80.86 \%$ of the variance, as shown in Table 2 .

Table 2. Component matrix of exploratory factor analysis for osteoporosis self-efficacy scale Arabic version (OSES-A).

\begin{tabular}{|c|c|c|c|c|c|}
\hline \multirow{2}{*}{ 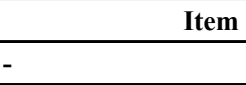 } & \multicolumn{2}{|c|}{ Pattern Matrix } & \multicolumn{2}{|c|}{ Structure Matrix } & \multirow{2}{*}{ Communalities } \\
\hline & Factor 1 & Factor 2 & Factor 1 & Factor 2 & \\
\hline Question 1 & 0.894 & - & 0.910 & - & 0.829 \\
\hline Question 2 & 0.950 & - & 0.924 & - & 0.858 \\
\hline Question 3 & 0.943 & - & 0.945 & - & 0.894 \\
\hline Question 4 & 0.932 & - & 0.923 & - & 0.852 \\
\hline Question 5 & 0.923 & - & 0.935 & - & 0.876 \\
\hline Question 6 & 0.891 & - & 0.907 & - & 0.824 \\
\hline Question 7 & - & 0.815 & - & 0.829 & 0.689 \\
\hline Question 8 & - & 0.883 & - & $\mathbf{0 . 8 7 7}$ & 0.770 \\
\hline Question 9 & - & 0.94 & - & 0.900 & 0.821 \\
\hline Question 10 & - & 0.915 & - & 0.907 & 0.823 \\
\hline Question 11 & - & 0.884 & - & 0.889 & 0.790 \\
\hline Question 12 & - & 0.760 & - & 0.812 & 0.678 \\
\hline Eigenvalues & 6.661 & 3.042 & - & - & - \\
\hline$\%$ of variance & 55.51 & 25.35 & - & - & Total $=\mathbf{8 0 . 8 6} \%$ \\
\hline Cronbach's (a) & 0.966 & 0.935 & - & - & Total OSES-A=0.927 \\
\hline
\end{tabular}

Extraction Method: Principal Axis Factoring, Rotation Method: Oblimin with Kaiser Normalization, Factor 1= OSES-Exercise-, Factor 2= OSESCalcium, Items comprising each factor are in bold.

In addition, the eigenvalues of Factor 1 (OSES-M Exercise subscale) and Factor 2 (OSES-M Calcium subscale) explained $55.51 \%$ and $25.35 \%$ of the variance, respectively. The entire results showed adequacy for factor analysis and with two domain (subscales) variables.

\subsubsection{Reliability}

For the reliability, the Cronbach's alpha test of internal consistency for total OSES-A, 0.927 and it's within the recommended acceptable result for reliability [33]. Test-retest reliabilities of OSES-A demonstrated significantly positive relationships in a sample of 25 subjects $(r=0.859, P<0.001)$. An initial Cronbach's alpha result for the OSES-A test-retest group was 0.719 , and after 1 to 2 weeks it was 0.798 . These results demonstrated that OSES-A was reliable and stable. The corrected item-total correlation values, which is the reliability index, ranged from 0.556 to 0.795 (Table 3). All items appeared to be suitable for retention depending on the meaningfulness of the items [19].

Table 3. Reliability test of the osteoporosis self-efficacy scale Arabic version (OSES-A).

\begin{tabular}{|c|c|c|c|c|}
\hline OSES-A Question No. & Mean & Standard Deviation & Corrected Item-Total Correlation & Cronbach's Alpha if Item Deleted \\
\hline Question 1 & 50.70 & 27.60 & 0.772 & 0.917 \\
\hline Question 2 & 47.93 & 27.96 & 0.725 & 0.919 \\
\hline Question 3 & 53.07 & 27.53 & 0.790 & 0.916 \\
\hline Question 4 & 48.03 & 28.34 & 0.748 & 0.918 \\
\hline Question 5 & 52.00 & 27.30 & 0.795 & 0.916 \\
\hline Question 6 & 54.43 & 27.65 & 0.769 & 0.917 \\
\hline Question 7 & 56.73 & 23.06 & 0.593 & 0.924 \\
\hline Question 8 & 59.50 & 21.90 & 0.597 & 0.924 \\
\hline Question 9 & 60.47 & 21.04 & 0.556 & 0.925 \\
\hline Question 10 & 60.20 & 20.85 & 0.618 & 0.923 \\
\hline
\end{tabular}


(Table 3) contd.....

\begin{tabular}{|c|c|c|c|c|}
\hline OSES-A Question No. & Mean & Standard Deviation & Corrected Item-Total Correlation & Cronbach's Alpha if Item Deleted \\
\hline Question 11 & 60.10 & 21.49 & 0.624 & 0.923 \\
\hline Question 12 & 55.27 & 21.35 & 0.648 & 0.922 \\
\hline
\end{tabular}

Cronbach's alpha was 0.927 for the total scale

\subsection{Multivariate and Correlation Analysis}

Correlations were performed to determine the relationship between total OKT-A and OHBS-A with total OSES-A. There were positive correlations between total OSES-A score with total OKT-A score, $r=0.274$, and OHBS-A, $r=0.238$ (all $P_{S}<0.01$ ). The binary logistic regression revealed that OKT-A (categorical) and OHBS-A (categorical), age (continuous) and gender were predictors for total OSES-A (Table 4) and the model explain about $84.70 \%$ of the dependent variable.

Table 4. Multivariate regression analysis summary.

\begin{tabular}{|c|c|c|c|c|}
\hline \multirow{2}{*}{ Variables Included } & \multirow[b]{2}{*}{ B (SE) } & \multicolumn{3}{|c|}{ 95\% CI for Odds Ratio } \\
\hline & & Lower & Odds ratio & Upper \\
\hline Constant & $-0.879(0.634)$ & & & \\
\hline OKT-A (categorical) & $1.219(0.342)^{b}$ & 1.730 & 3.384 & 6.619 \\
\hline OHBS-A (categorical) & $0.916(0.342)^{b}$ & 1.279 & 2.499 & 4.882 \\
\hline Age (continuous) & $-0.032(0.014)^{\mathrm{a}}$ & 0.942 & 0.969 & 0.997 \\
\hline Gender & $-0.833(0.342)^{\mathrm{a}}$ & 0.222 & 0.435 & 0.850 \\
\hline
\end{tabular}

Note: $R^{2}=0.442$ (Hosmer \& Lemeshow), 0.118 (Cox \& Snell), 0.198 (Nagelkerke). Model $_{X}{ }^{2}(4)=37.52, P<0.001 .{ }^{a} P<0.05,{ }^{* *} P<0.01$.

\section{DISCUSSION}

Self-efficacy is the opinion and the attitude to engage and maintain activity in face of obstacles [36]. To reduce the risk of future bone fractures, osteoporosis prevention by the mean of educational program is the most effective way [37, 38]. Moreover, before any educational program to be implemented, the knowledge, health belief and self-efficacy must be assessed so that the program could be tailored according to the required need for the population.

In this study, the OSES-A was carefully reviewed and revised by a panel of eight experts in the pharmacy field after forward-backward-forward translation for face validity process. The EFA of the OSES-A has a stable factor structure with two factors accounted for $80.86 \%$ of the variance, which was higher than other studies [24,39,22]. This result may be due to different culture setting i.e., nations, cultures and times as compared with the US population where the original tool developed in 1991. This highlights the important of cross-cultural adaptation process even for wellestablished questionnaires.

The reliability of the OSES-A which is the consistency of a measurement item, was an excellent with overall Cronbach's alpha (0.927). This value was comparable to the original OSES, Malaysian and Persian studies [24, 39, 22]. The test-retest reliability Cronbach's alpha value after 1-2 weeks was higher than the initial value indicating that the respondents may be more aware and more confident in engaging in healthier behaviors. Therefore, this could be used in longitudinal studies to measure the change in self-efficacy level and, consequently, improve their outcome. The validity and reliability results revealed successful cultural adaptation.

The results showed low frequencies in all dimensions with low overall self-efficacy score. The total OSES-A score for men was significantly higher than women. In addition, after controlling gender, men in both age groups showed insignificant results, while for women, younger age $(<45)$ had higher self-efficacy. The OSES-A exercise subscale for men (frequency 58.24\%) was higher than women (frequency $44.89 \%$ ), however, this result was insignificant. This is an important result as it showed that any educational program should be highly focuses on highly risk group (i.e., women). Previous literatures showed that the self-efficacy scores for men were higher than women [40, 41]. Moreover, Nayak et al. showed that the health belief was higher in younger than older age groups which affect the final preventive behaviors [42]. However, any program should be taken in to account both age groups and genders. The above result was consistent with the significant correlations between OSES-A score and the OKT-A and OHBS-A. The results were consistent with other studies which showed that increasing knowledge and health belief were positively affect selfefficacy $[41,43,44]$.

Furthermore, by controlling OKT-A, the respondents with a history of OP were negatively correlated with the total 
OSES-A scores and OSES-A exercise subscale only. This was obvious as the pain gained from OP would prevent those participants to engage in different exercise behaviors. Shin et al. showed that the commitment to engage any exercise were differed according to the severity of pain and the intervention must be tailored according to the subjects need [18]. The results showed low OSES-A exercise subscale score. Therefore, the educational program should be focused on that regular exercise not only increase bone strength, but improve mood and physiological function, reduce frequency of disease, increase the quality of life [45 - 49].

In Iraq, there are no free public gym centers, running in the streets is not acceptable culturally, and women engaged in exercise also not acceptable. Other study showed that inconvenience, cost and time were the factors barriers for engaging exercise [50]. To overcome these barriers and for better health, a new policies must be implemented like the availability of free of charge public gyms. Moreover, encouraging and changing the attitude and belief of the community regarding the engagement in the exercise (especially for women) should be enhanced.

The results showed low mean score for OSES-A calcium subscale. This result must be highlighted in any interventional program. Enhance the awareness of the general population should be focused on that calcium-rich foods not only improve bone health but also improve weight lost, decrease the incidence of metabolic syndrome, decrease blood pressure [51 - 55]. The educator should also emphasis on increasing the knowledge of the participants about what the alternatives which are not costly and suitable for their needs. Also, the participants should know that there is no association between dairy products and the metabolic disorders [55 - 57]. Besides that, adequate calcium intake in the adolescents age were the peak bone density developed must be highlighted too [58]. Therefore, the attitude of the respondents in this study could be increased by means of the initiation of an effective prevention program, increasing the risk reducing behaviors and good coping strategies.

This study cannot be generalized for all population as it is a cross sectional study. Nevertheless, the comprehensive translation and validation steps with a good sample size and cluster sampling method give a high impact for this study.

\section{CONCLUSION}

This study showed good psychometric properties of OSES-A tool and could be used in clinical setting or with general population. Furthermore, increasing osteoporosis self-efficacy of Iraqi population in all dimensions (exercise and calcium intake) is warranted as changing lifestyle and healthy behaviors will have a greater impact on the prevalence of osteoporosis.

\section{ETHICS APPROVAL AND CONSENT TO PARTICIPATE}

The study protocol and ethical approval (including verbal informed consent) were approved by the Scientific Committee of Al-Rafidain University Collage, Baghdad, Iraq.

\section{HUMAN AND ANIMAL RIGHTS}

No animals/humans were used for studies that are the basis of this review.

\section{CONSENT FOR PUBLICATION}

A written informed consent was obtained from all participants when they were enrolled.

\section{CONFLICT OF INTEREST}

The author declares no conflict of interest, financial or otherwise.

\section{ACKNOWLEDGEMENTS}

Declared none.

\section{REFERENCES}

[1] Cummings SR, Melton LJ. Epidemiology and outcomes of osteoporotic fractures. Lancet 2002; 359(9319): $1761-7$. [http://dx.doi.org/10.1016/S0140-6736(02)08657-9] [PMID: 12049882]

[2] Piaseu N, Belza B, Mitchell P. Testing the effectiveness of an osteoporosis educational program for nursing students in Thailand. Arthritis Rheum 2001; 45(3): 246-51. [http://dx.doi.org/10.1002/1529-0131(200106)45:3<246::AID-ART256>3.0.CO;2-Y] [PMID: 11409665] 
[3] Anderson KD, Chad KE, Spink KS. Osteoporosis knowledge, beliefs, and practices among adolescent females. J Adolesc Health 2005; 36(4): 305-12. [http://dx.doi.org/10.1016/j.jadohealth.2004.03.007] [PMID: 15780785]

[4] Bohaty K, Rocole H, Wehling K, Waltman N. Testing the effectiveness of an educational intervention to increase dietary intake of calcium and vitamin D in young adult women. J Am Acad Nurse Pract 2008; 20(2): 93-9. [http://dx.doi.org/10.1111/j.1745-7599.2007.00281.x] [PMID: 18271764]

[5] Siris ES, Chen Y-T, Abbott TA, et al. Bone mineral density thresholds for pharmacological intervention to prevent fractures. Arch Intern Med 2004; 164(10): 1108-12. [http://dx.doi.org/10.1001/archinte.164.10.1108] [PMID: 15159268]

[6] Uusi-Rasi K, Sievänen H, Pasanen M, Oja P, Vuori I. Association of physical activity and calcium intake with the maintenance of bone mass in premenopausal women. Osteoporos Int 2002; 13(3): 211-7. [http://dx.doi.org/10.1007/s001980200016] [PMID: 11991440]

[7] Gurney S, Simmonds J. Osteoporosis: A teenage perspective. Physiotherapy 2007; 93: 267-72. [http://dx.doi.org/10.1016/j.physio.2006.12.004]

[8] Sedlak CA, Doheny MO, Jones SL. Osteoporosis education programs: Changing knowledge and behaviors. Public Health Nurs 2000; 17(5): $398-402$. [http://dx.doi.org/10.1046/j.1525-1446.2000.00398.x] [PMID: 11013003]

[9] von Hurst PR, Wham CA. Attitudes and knowledge about osteoporosis risk prevention: A survey of New Zealand women. Public Health Nutr 2007; 10(7): 747-53.

[http://dx.doi.org/10.1017/S1368980007441477] [PMID: 17381949]

[10] Ford MA, Bass M, Zhao Y, Bai J-B, Zhao Y. Osteoporosis knowledge, self-efficacy, and beliefs among college students in the USA and China. J Osteoporos 2011; 2011: 729219. [http://dx.doi.org/10.4061/2011/729219] [PMID: 21603144]

[11] Kasper MJ, Peterson MG, Allegrante JP. The need for comprehensive educational osteoporosis prevention programs for young women: Results from a second osteoporosis prevention survey. Arthritis Rheum 2001; 45(1): 28-34. [http://dx.doi.org/10.1002/1529-0131(200102)45:1<28::AID-ANR80>3.0.CO;2-G] [PMID: 11308058]

[12] Lee LY, Lai EK. Osteoporosis in older Chinese men: knowledge and health beliefs. J Clin Nurs 2006; 15(3): 353-5. [http://dx.doi.org/10.1111/j.1365-2702.2006.01303.x] [PMID: 16466485]

[13] Ozturk A, Sendir M. Evaluation of knowledge of osteoporosis and self-efficacy perception of female orthopaedic patients in Turkey. J Nurs Healthc Chronic Illn 2011; 3: 319-28.

[http://dx.doi.org/10.1111/j.1752-9824.2011.01106.x]

[14] Bandura A. Self-efficacy: Toward a unifying theory of behavioral change. Psychol Rev 1977; 84(2): $191-215$. [http://dx.doi.org/10.1037/0033-295X.84.2.191] [PMID: 847061]

[15] Blamey R, Jolly K, Greenfield S, Jobanputra P. Patterns of analgesic use, pain and self-efficacy: A cross-sectional study of patients attending a hospital rheumatology clinic. BMC Musculoskelet Disord 2009; 10: 137. [http://dx.doi.org/10.1186/1471-2474-10-137] [PMID: 19903350]

[16] Elliott JO, Jacobson MP, Seals BF. Self-efficacy, knowledge, health beliefs, quality of life, and stigma in relation to osteoprotective behaviors in epilepsy. Epilepsy Behav 2006; 9(3): 478-91. [http://dx.doi.org/10.1016/j.yebeh.2006.07.007] [PMID: 16935031]

[17] Pells JJ, Shelby RA, Keefe FJ, et al. Arthritis self-efficacy and self-efficacy for resisting eating: Relationships to pain, disability, and eating behavior in overweight and obese individuals with osteoarthritic knee pain. Pain 2008; 136(3): 340-7. [http://dx.doi.org/10.1016/j.pain.2007.07.012] [PMID: 17764844]

[18] Shin YH, Hur HK, Pender NJ, Jang HJ, Kim M-S. Exercise self-efficacy, exercise benefits and barriers, and commitment to a plan for exercise among Korean women with osteoporosis and osteoarthritis. Int J Nurs Stud 2006; 43(1): 3-10. [http://dx.doi.org/10.1016/j.ijnurstu.2004.10.008] [PMID: 16326159]

[19] Streiner DL, Norman GR, Cairney J. Health measurement scales: a practical guide to their development and use. USA: Oxford University Press 2015. [http://dx.doi.org/10.1093/med/9780199685219.001.0001]

[20] Field A. Discovering statistics using SPSS. Sage publications 2009.

[21] Dawson-Saunders B, Trapp RG. Basic and clinical biostatistics. New York: Lange Medical Books/McGraw-Hill 2004.

[22] Horan ML, Kim KK, Gendler P, Froman RD, Patel MD. Development and evaluation of the osteoporosis self-efficacy scale. Res Nurs Health 1998; 21(5): 395-403. [http://dx.doi.org/10.1002/(SICI)1098-240X(199810)21:5<395::AID-NUR3>3.0.CO;2-I] [PMID: 9761137]

[23] Kim K, Horan M, Gendler P. Osteoporosis knowledge tests, osteoporosis health belief scale, and osteoporosis self-efficacy scale. Allendale, MI: Grand Valley State University 1991.

[24] Abdulameer SA, Syed Sulaiman SA, Hassali MA, Subramaniam K, Sahib MN. Psychometric properties and osteoprotective behaviors among 
type 2 diabetic patients: osteoporosis self-efficacy scale Malay version (OSES-M). Osteoporos Int 2013; 24(3): 929-40. [http://dx.doi.org/10.1007/s00198-012-2071-1] [PMID: 22790611]

[25] Kim KK, Horan ML, Gendler P, Patel MK. Development and evaluation of the osteoporosis health belief scale. Res Nurs Health 1991; 14(2): 155-63. [http://dx.doi.org/10.1002/nur.4770140210] [PMID: 2047537]

[26] Abdulameer SA, Syed Sulaiman SA, Hassali MA, Sahib MN, Subramaniam K. Psychometric properties of the Malay version of the Osteoporosis Health Belief Scale (OHBS-M) among Type 2 diabetic patients. Int J Rheum Dis 2014; 17(1): 93-105. [http://dx.doi.org/10.1111/1756-185X.12104] [PMID: 24472272]

[27] Abdulameer SA, Syed Sulaiman SA, Hassali MA, Subramaniam K, Sahib MN. Psychometric properties of Osteoporosis Knowledge Tool and self-management behaviours among Malaysian type 2 diabetic patients. J Community Health 2013; 38(1): 95-105. [http://dx.doi.org/10.1007/s10900-012-9586-4] [PMID: 22772955]

[28] Beaton DE, Bombardier C, Guillemin F, Ferraz MB. Guidelines for the process of cross-cultural adaptation of self-report measures. Spine 2000; 25(24): 3186-91. [http://dx.doi.org/10.1097/00007632-200012150-00014] [PMID: 11124735]

[29] Guillemin F, Bombardier C, Beaton D. Cross-cultural adaptation of health-related quality of life measures: Literature review and proposed guidelines. J Clin Epidemiol 1993; 46(12): 1417-32. [http://dx.doi.org/10.1016/0895-4356(93)90142-N] [PMID: 8263569]

[30] Wild D, Grove A, Martin M, et al. Principles of good practice for the translation and cultural adaptation process for patient-reported outcomes (PRO) measures: report of the ISPOR task force for translation and cultural adaptation. Value Health 2005; 8(2): $94-104$. [http://dx.doi.org/10.1111/j.1524-4733.2005.04054.x] [PMID: 15804318]

[31] DeVon HA, Block ME, Moyle-Wright P, et al. A psychometric toolbox for testing validity and reliability. J Nurs Scholarsh 2007; 39(2): 155-64. [http://dx.doi.org/10.1111/j.1547-5069.2007.00161.x] [PMID: 17535316]

[32] Fabrigar LR, Wegener DT, MacCallum RC, Strahan EJ. Evaluating the use of exploratory factor analysis in psychological research. Psychol Methods 1999; 4: 272-99.

[http://dx.doi.org/10.1037/1082-989X.4.3.272]

[33] Cronbach LJ. Coefficient alpha and the internal structure of tests. psychometrika 1951; 16: $297-334$.

[34] Bartlett MS. Tests of significance in factor analysis. Br J Math Stat Psychol 1950; 3: 77-85. [http://dx.doi.org/10.1111/j.2044-8317.1950.tb00285.x]

[35] Bartlett MS. A further note on tests of significance in factor analysis. Br J Math Stat Psychol 1951; 4: 1-2. [http://dx.doi.org/10.1111/j.2044-8317.1951.tb00299.x]

[36] Turner LW, Hunt SB, Dibrezzo R, Jones C. Design and implementation of an osteoporosis prevention program using the health belief model. Am J Health Stud 2004; 19: 115-21.

[37] Chan MF, Ko CY, Day MC. The effectiveness of an osteoporosis prevention education programme for women in Hong Kong: A randomized controlled trial. J Clin Nurs 2005; 14(9): 1112-23.

[http://dx.doi.org/10.1111/j.1365-2702.2005.01224.x] [PMID: 16164529]

[38] Karinkanta S, Piirtola M, Sievänen H, Uusi-Rasi K, Kannus P. Physical therapy approaches to reduce fall and fracture risk among older adults. Nat Rev Endocrinol 2010; 6(7): 396-407. [http://dx.doi.org/10.1038/nrendo.2010.70] [PMID: 20517287]

[39] Baheiraei A, Ritchie JE, Eisman JA, Nguyen TV. Psychometric properties of the Persian version of the osteoporosis knowledge and health belief questionnaires. Maturitas 2005; 50(2): 134-9. [http://dx.doi.org/10.1016/j.maturitas.2004.05.001] [PMID: 15653011]

[40] Barzanji AT, Alamri FA, Mohamed AG. Osteoporosis: a study of knowledge, attitude and practice among adults in Riyadh, Saudi Arabia. J Community Health 2013; 38(6): 1098-105. [http://dx.doi.org/10.1007/s10900-013-9719-4] [PMID: 23780302]

[41] Doheny MO, Sedlak CA, Estok PJ, Zeller R. Osteoporosis knowledge, health beliefs, and DXA T-scores in men and women 50 years of age and older. Orthop Nurs 2007; 26(4): 243-50. [http://dx.doi.org/10.1097/01.NOR.0000284654.68215.de] [PMID: 17882102]

[42] Nayak S, Roberts MS, Chang C-CH, Greenspan SL. Health beliefs about osteoporosis and osteoporosis screening in older women and men. Health Educ J 2010; 69(3): 267-76. [http://dx.doi.org/10.1177/0017896910364570] [PMID: 21643516]

[43] Francis KL, Matthews BL, Van Mechelen W, Bennell KL, Osborne RH. Effectiveness of a community-based osteoporosis education and selfmanagement course: A wait list controlled trial. Osteoporos Int 2009; 20(9): 1563-70. [http://dx.doi.org/10.1007/s00198-009-0834-0] [PMID: 19194641]

[44] Sedlak CA, Doheny MO, Estok PJ. Osteoporosis in older men: knowledge and health beliefs. Orthop Nurs 2000; 19(3): 38-42, 44-46. [http://dx.doi.org/10.1097/00006416-200019030-00006] [PMID: 11153331] 
[45] Bize R, Johnson JA, Plotnikoff RC. Physical activity level and health-related quality of life in the general adult population: A systematic review. Prev Med 2007; 45(6): 401-15. [http://dx.doi.org/10.1016/j.ypmed.2007.07.017] [PMID: 17707498]

[46] De Moor MHM, Beem AL, Stubbe JH, Boomsma DI, De Geus EJC. Regular exercise, anxiety, depression and personality: A populationbased study. Prev Med 2006; 42(4): 273-9. [http://dx.doi.org/10.1016/j.ypmed.2005.12.002] [PMID: 16439008]

[47] Kokkinos PF, Narayan P, Colleran JA, et al. Effects of regular exercise on blood pressure and left ventricular hypertrophy in AfricanAmerican men with severe hypertension. N Engl J Med 1995; 333(22): 1462-7. [http://dx.doi.org/10.1056/NEJM199511303332204] [PMID: 7477146]

[48] Kraus WE, Slentz CA. Exercise training, lipid regulation, and insulin action: A tangled web of cause and effect. Obesity (Silver Spring) 2009; 17(Suppl. 3): S21-6. [http://dx.doi.org/10.1038/oby.2009.384] [PMID: 19927141]

[49] Radak Z, Chung HY, Koltai E, Taylor AW, Goto S. Exercise, oxidative stress and hormesis. Ageing Res Rev 2008; 7(1): $34-42$. [http://dx.doi.org/10.1016/j.arr.2007.04.004] [PMID: 17869589]

[50] Sedlak CA, Doheny MO, Jones SL. Osteoporosis prevention in young women. Orthop Nurs 1998; 17(3): 53-60. [http://dx.doi.org/10.1097/00006416-199805000-00009] [PMID: 9847819]

[51] Ascherio A, Hennekens C, Willett WC, et al. Prospective study of nutritional factors, blood pressure, and hypertension among US women. Hypertension 1996; 27(5): 1065-72. [http://dx.doi.org/10.1161/01.HYP.27.5.1065] [PMID: 8621198]

[52] Azadbakht L, Mirmiran P, Esmaillzadeh A, Azizi F. Dairy consumption is inversely associated with the prevalence of the metabolic syndrome in Tehranian adults. Am J Clin Nutr 2005; 82(3): 523-30. [http://dx.doi.org/10.1093/ajen/82.3.523] [PMID: 16155263]

[53] Davies KM, Heaney RP, Recker RR, et al. Calcium intake and body weight. J Clin Endocrinol Metab 2000; 85(12): 4635-8. [PMID: 11134120]

[54] Mirmiran P, Esmaillzadeh A, Azizi F. Dairy consumption and body mass index: An inverse relationship. Int J Obes 2005; 29(1): 115-21. [http://dx.doi.org/10.1038/sj.ijo.0802838] [PMID: 15534616]

[55] Pereira MA, Jacobs DR Jr, Van Horn L, Slattery ML, Kartashov AI, Ludwig DS. Dairy consumption, obesity, and the insulin resistance syndrome in young adults: The CARDIA Study. JAMA 2002; 287(16): 2081-9. [http://dx.doi.org/10.1001/jama.287.16.2081] [PMID: 11966382]

[56] Beydoun MA, Gary TL, Caballero BH, Lawrence RS, Cheskin LJ, Wang Y. Ethnic differences in dairy and related nutrient consumption among US adults and their association with obesity, central obesity, and the metabolic syndrome. Am J Clin Nutr 2008; 87(6): $1914-25$. [http://dx.doi.org/10.1093/ajcn/87.6.1914] [PMID: 18541585]

[57] Phillips SM, Bandini LG, Cyr H, Colclough-Douglas S, Naumova E, Must A. Dairy food consumption and body weight and fatness studied longitudinally over the adolescent period. Int J Obes Relat Metab Disord 2003; 27(9): 1106-13. [http://dx.doi.org/10.1038/sj.ijo.0802370] [PMID: 12917718]

[58] Bronner YL, Hawkins AS, Holt ML, et al. Models for nutrition education to increase consumption of calcium and dairy products among African Americans. J Nutr 2006; 136(4): 1103-6.

[http://dx.doi.org/10.1093/jn/136.4.1103] [PMID: 16549488]

(C) 2018 Mohanad Naji Sahib .

This is an open access article distributed under the terms of the Creative Commons Attribution 4.0 International Public License (CC-BY 4.0), a copy of which is available at: https:/creativecommons.org/licenses/by/4.0/legalcode. This license permits unrestricted use, distribution, and reproduction in any medium, provided the original author and source are credited. 